\title{
Research of critical energy infrastructures taking into account energy security
}

\author{
Natalia Pyatkova ${ }^{1, *}$, Natalia Beresneva $^{1}$, Alexey Edelev ${ }^{1}$ \\ ${ }^{1}$ Melentiev Energy Systems Institute, 130 Lermontov str., Irkutsk, Russia
}

\begin{abstract}
The article suggests an approach to the study of critical energy infrastructures. The existing definitions of the critical infrastructure are given, the feasibility of researching the fuel and energy complex combining the energy systems as a critical infrastructure is justified. The developed models for carrying out research to identify critical objects in the energy sector are presented. A developed package of applied programs for calculating and analyzing FEC states in dynamics as a critical infrastructure is described.
\end{abstract}

\section{Introduction}

Investigations of critical infrastructures have become one of the new directions for research of reliable energy supply to consumers in conditions at a high level of development of information technologies.

Abroad, studies of critical infrastructures began in the 90 s of the last century [1-3], research centers have been established.

At the same time, in our country the terminology on critical infrastructures is currently not settled. In particular, in [4] critical is understood "infrastructure, the elements of which are of particular importance for the state and society, the failure or limitation of performance would lead to long disruptions in supply, serious violations of public security or other dramatic consequences" In accordance with this definition to critical infrastructures with complete certainty includes sectoral energy systems and the fuel and energy complex (FEC), which is an interconnected infrastructure, consisting of separate energy systems. This is confirmed by the importance of these structures for the economy of the state and society and is the main part of researching the problems of the country's energy security.

\section{Research of critical energy infrastructures work from the positions of energy security}

The energy security of the country and its regions is essentially a balance of energy supply and demand [5]. The main content of research tasks to ensure energy security is:

- forecasting the conditions of functioning and development of energy systems (ES, ie critical infrastructures) and the fuel and energy complex (a complex consisting of critical infrastructures), taking into account possible emergency situations (critical and emergency situations);

- assessment of the condition of the energy systems in these conditions, identification of potential critical objects $(\mathrm{CO})$ in them;

- selection of possible directions and measures to prevent or reduce the negative impact of contingencies, taking into account specialized safety measures (reserves and holdings), as well as the capabilities of the energy systems for critical (CS) or emergency (ES) situations (partitioning systems for localization of accidents, regulation energy consumption, disconnection of individual consumers, etc.).

Studies of critical energy infrastructures from the ES standpoint are carried out in the framework of computational experiments based on the information base presented by the technical and economic characteristics of energy facilities, reporting data on the state of energy systems, and the results of research into the development of the fuel and energy complex. These studies are based on the territorial-production models of the fuel and energy complex, reflecting the technological cycle of energy resource transformations, imitating the work of key industry objects under given operating conditions. The main research tool is information support programs for modeling FEC states in abnormal situations, with subsequent calculation and evaluation of these states. An important component of the state assessment is the identification of potential $\mathrm{CO}$, the determination of the degree of their criticality in the context of the situations studied. CO in this case are the most vulnerable elements of critical infrastructures, which can cause significant disruptions in the operation of reliable energy supply to consumers. Therefore, when allocating the $\mathrm{CO}$ in the fuel and energy complex, the conditions for the maximum possible satisfaction of consumers should be taken into account in case of

* Corresponding author: beresneva@isem.irk.ru 
realization of contingencies. This task is directly related to:

- identification and neutralization of various threats to sustainable fuel and energy supply;

- analysis and assessment of the energy systems state in the CS and ES, which are the implementation of ES threats;

- advance preparation of FEC facilities and systems for operation during emergencies caused by the implementation of threats of various types.

In practice, the emergence of abnormal situations is associated with the implementation of natural (cooling) and technogenic (transport accidents, energy production and production facilities) threats. When realizing natural hazards, deviations of the maximum seasonal heating loads of regions can be observed depending on their climatic conditions and on the composition of consumers in them up to $20-30 \%$. This may be accompanied by a significant increase in demand for energy resources for both the single climatic zone and several neighboring regions.

Technogenic threats are most critical for the gas industry and the power industry. In the gas supply system, one of the most dangerous factors is the possibility of damaging transcontinental gas pipelines coming from a large gas producing region through the Urals to the European part of Russia. In the electric power industry, significant shortages can be caused by disconnections between individual power systems or emergencies at specific power plants (for example, a major accident in the Moscow power system in 2005 at the Chagino substation, an accident at the Sayano-
Shushenskaya HPP in 2009, a system accident at the power facilities of the SFO due to a failure at the Bratsk hydropower plant in June 2017).

It is possible to evaluate the functioning of systems under these conditions in the framework of model studies based on the apparatus of dual estimates [7]. Dual estimates in this case can serve as a measure of the scarcity of a resource, while showing how changing the restriction of this resource per unit can lead to a change in the value of the objective function by the value of the dual estimate [6]. In our case, such a resource may be the production capabilities of the technological methods under consideration (capacity for extraction, production, transportation of energy resources, stocks for different purposes). For objects whose production capacity is sufficient to perform the required technological operations, the value of the corresponding dual variable will be zero. For potential $\mathrm{CO}$, the values of the dual variable will be less than zero. The priority of the $\mathrm{CO}$ in this case is determined by ranking the values of increments in production capacities. Assessment of the state of systems in critical and emergency situations is supposed to be carried out on the basis of economicmathematical models and research tools described below. A generalized scheme of model studies of critical energy infrastructures from the standpoint of providing ES is shown in Fig. 1

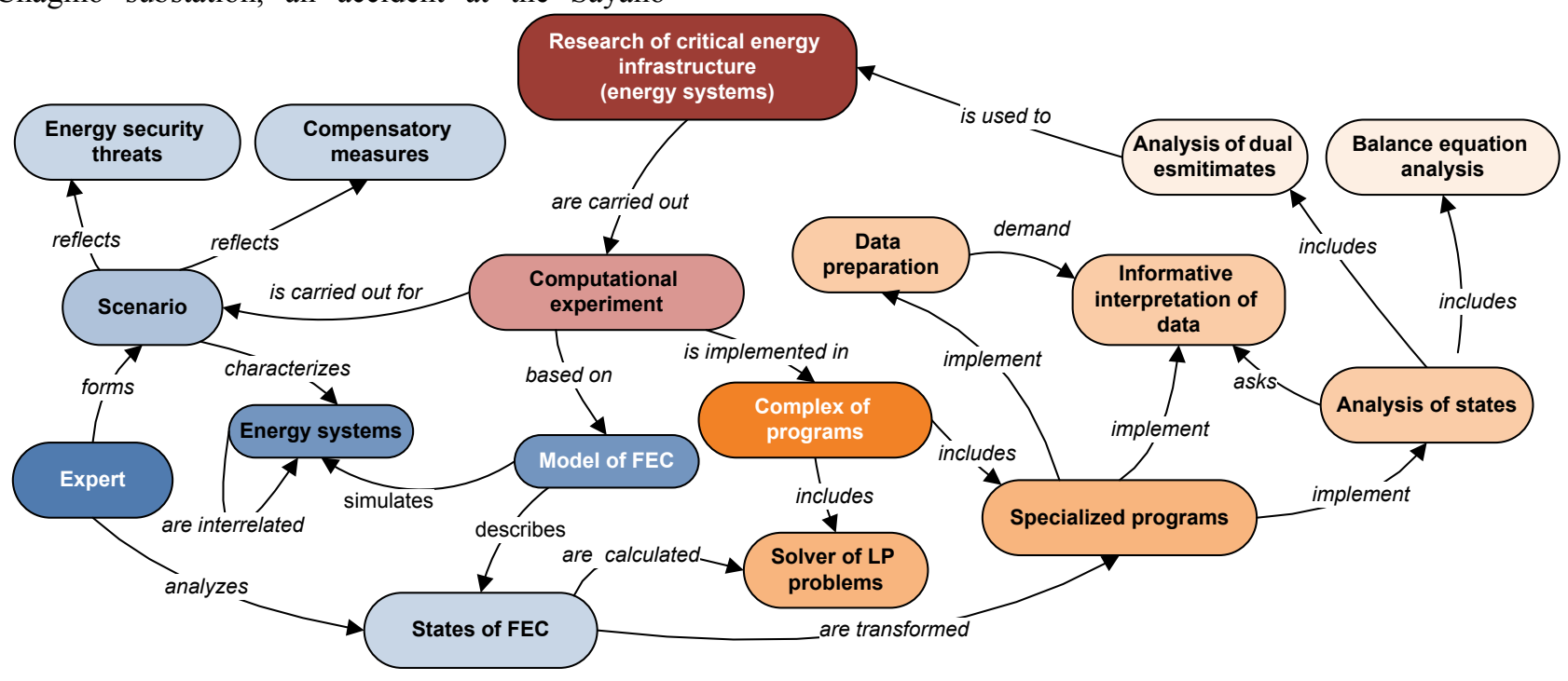

Fig. 1. Scheme for model studies of critical energy infrastructures

\section{System of mathematical models for the study of critical infrastructures from the of energy security positions}

A review of the work of foreign researchers on the modeling of critical infrastructures showed that these models have features that allow them to be applied only for these countries [8].
At present, a large number of models [9] have been developed in foreign countries for the study of ship systems, campuses, large electricity distribution networks, waterways and much more, and their main task has been to integrate them into a single hardware and software system that will provide managers with appropriate the ability to make an informed and correct decision, getting a reply to the question "what needs to be protected or hit and how much it will cost (spend ie the efforts and resources)". 
Therefore, to study the behavior of Russia's critical energy infrastructures, original models for these studies were proposed.

Possible large-scale consequences from emergency situations in the energy sector require a special analysis of the behavioral features of critical infrastructures (energy systems) near their ultimate state. To carry out this analysis is possible only in the case of a hierarchy of studies based on FEC models. Only such a scheme of calculations will provide the conditions for obtaining and coordinating the results of research on the functional properties of individual energy systems and structural relationships in the fuel and energy sector, and will jointly take into account the physico-technical and technical-economic characteristics of the objects under consideration. At the same time, two tasks must be solved:

- the task of allocating potential CO in the operation of the fuel and energy sector in abnormal situations;
- the task of assessing the extent of their impact on the functioning of the fuel and energy complex in the context of the development of potential threats to ES.

These tasks are solved within the framework of the joint use of the models of the functioning and development of the fuel and energy complex, conceptually identical in the content aspect (Fig. 2), expressed in the allocation of fuel and energy resources, facilities (energy and economic-organizational) and multi-level territorial entities. Objects of models are described by technological and economic characteristics, processes in them (technologies) of resources conversion taking place. The nature of the latter determines the type of objects, identifies the energy (the objects of extraction and processing of resources, the objects of their storage and transportation) and organizational-economic (various categories of consumers, branch management organizations) objects. The interaction of objects, their association into groups and their territorial binding in models is regulated by managerial and organizational ties applicable, in particular, to territorial entities.

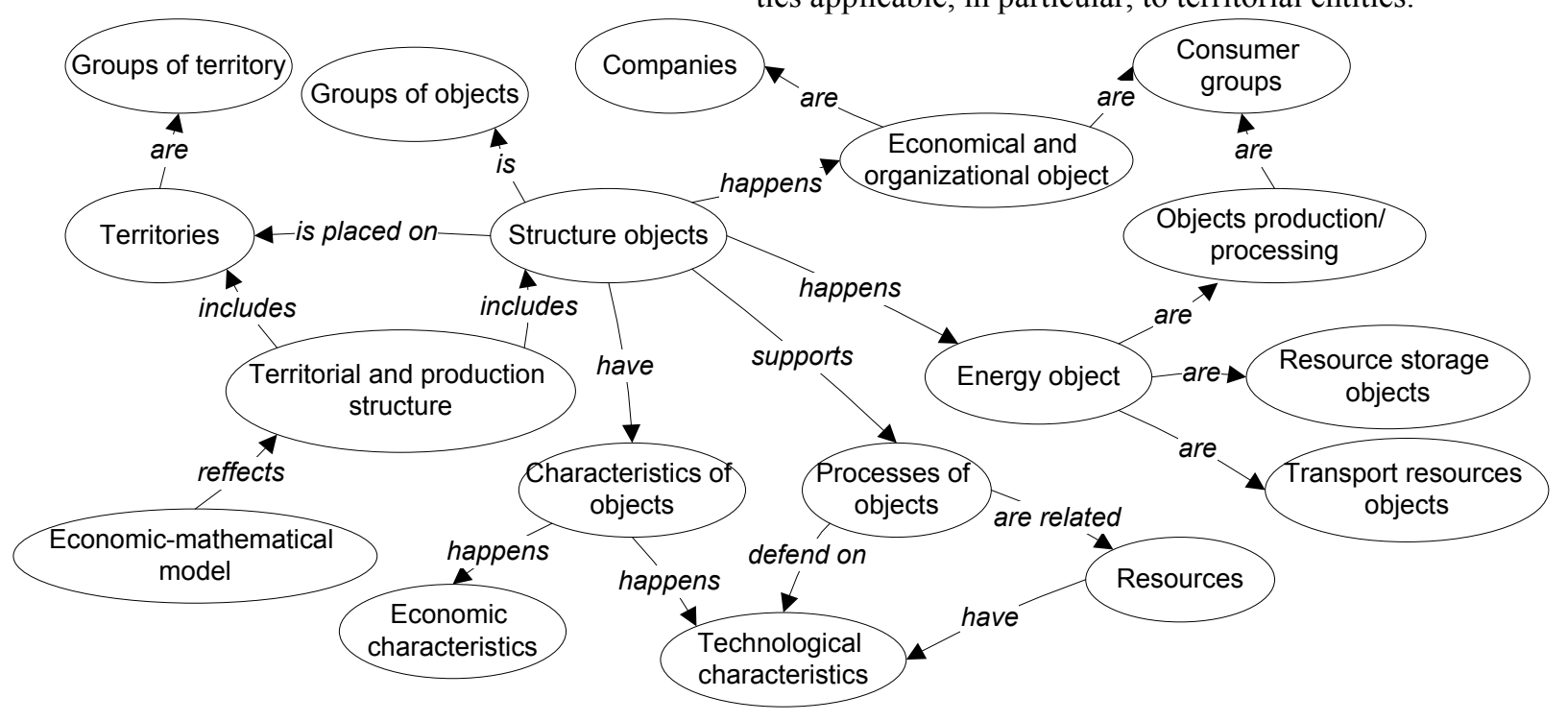

Fig. 2. The informative characteristic of the models for researches fuel energy complex

These models, different in the territorial, temporal and technological hierarchy, in the context of the interrelationship between the tasks of functioning and development of the fuel and energy complex, have the following features:

1. In the models of fuel and energy complex functioning there is a detailed representation of the objects, the working capacity of which is considered in three time intervals (from day to quarter). The need for such graduation is caused by the features of the operation of individual energy systems in emergency situations, with a maximum load of their production capacities, especially during the heating season (for example, taking into account the December maximum load in the electric power system and taking into account the daily gas withdrawals from the UGS at the end of the heating season). At the same time, administrative units of the country (as a rule, subjects of the Russian Federation) are considered territorially.
2. In the models of fuel and energy complex development, at the technological level, groups or types of fuel and energy complex are identified, tied to the federal districts of the country. At the same time, forecasting is carried out over time intervals in the annual section.

This model system is based on the model for estimating the territorial-production structure of the fuel and energy complex, taking into account the requirements of the $\mathrm{ES}$, which was considered in detail in $[5,10]$. This model can be used in two modes:

- in the mode of determining the optimal development of energy technologies (taking into account structural redundancy in the form of reserves of capacities, fuel reserves, interchangeability of energy resources) and optimal distribution of energy resources consumed, - in the mode of determining the shortage of energy resources (FER deficits) in the whole country and for individual regions. 
This model is characterized by the hierarchy of levels shown in Fig. 3. Technologically, it consists of sectoral subsystems of the energy complex (gas, coal, oil refining (in terms of fuel oil) industries, electricity and heat power).

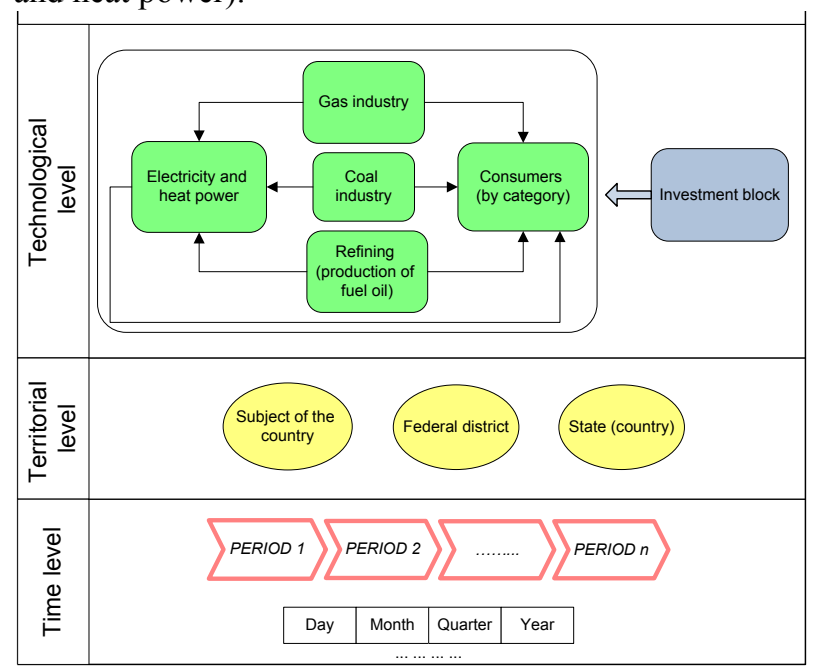

Fig. 3. Territorial, temporal and technological structure of the fuel and energy complex model

In the final implementation, it is supplemented by a financial unit describing the investment costs for the reconstruction, modernization of existing facilities, the withdrawal of obsolete equipment, the commissioning of new facilities at power industry facilities. It also takes into account the dynamics of the situation [11], which made it possible to trace such features of the multi-step process of the development of the fuel and energy sector, as:

- commissioning of new production facilities;

- dismantling and conservation of old facilities,

- reconstruction of facilities with changing technological scheme.

The dynamics in the model is taken into account in the form of $\mathrm{T}$ independent static blocks, each of which describes all the territorial and technological links of the fuel and energy complex as applied to stage $t$ of the settlement period. Dynamic relationships between blocks are constructed using equations that formulate for all $x_{j}$ objects of the FEC the condition of continuity of their productivity at different stages of the calculation period. For the first stage, this condition is written as

$$
x_{i 1}^{o}+x_{i 1}^{c}+x_{i 1}^{d}=P_{i 0}
$$

And for subsequent stages in the form of equations

where

$$
x_{i t-1}^{o}+x_{i t-1}^{c}+x_{i t-1}^{n}=x_{i t}^{o}+x_{i t}^{c}+x_{i t}^{d}
$$

$P_{i 0}$ - productivity (object) $i$ to the beginning of the calculation period,

$x_{i t-1}^{n}$ - productivity of the new part of the object $i$ on the stage $t-1$,

$x_{i t}^{o}$ - operating productivity (object) $i$ in a step $t$,

$x_{i t}^{c}$ - preservation of an object $i$ on the stage $t$, $x_{i t}^{d}$ - liquidation of the object $i$ on the stage $t$.

For the convenience of forming ties the equation (2) is divided into two parts

$$
\begin{gathered}
-x_{i t-1}^{o}-x_{i t-1}^{c}-x_{i t-1}^{n}+Z_{i t-1}=0 \\
-Z_{i t-1}+x_{i t}^{o}+x_{i t}^{c}+x_{i t}^{d}=0
\end{gathered}
$$

$Z_{i t-1}$ - intermediate variable characterizing the full performance of the object $i$ in the early stages $t$. It takes into account the power outflow in phase $t$ and the introduction of new power levels in the time step $t+1$.

In general, the model is used to determine the following characteristics (indicators):

- the size of shortages in certain types of energy resources for the categories of consumers considered, allocated to territorial associations and the country as a whole, as the magnitude of the discrepancy between the given demand and the possibility of producing this type of energy resource (taking into account reserves, the possibility of replacing this type of energy resource in others consumers, etc.);

- changes in the carrying capacity of inter-regional transport links, determined by comparing the corresponding indicators of the variant under consideration with the initial one;

- the recommended rational use of production capacities of energy facilities, as well as the distribution of certain types of energy resources by categories of consumers.

\section{Information support for research}

Information support for research on the dynamic model of the fuel and energy complex is realized in the modernized "universal" module of the distributed PPP "Corrective" [12]. Adaptation of this module required the organization of work with dynamic links of neighboring time states, in terms of the organization of calculations - the implementation of a new scheme for the formation of design files, conceptually expressed in the creation of a single file with descriptions of time states and communication equations between them. As a result of the adaptation, a software module with rigid data representation structures has been created that supports automatic data collection from sources (statistical reporting forms and subject databases), automatic generation of model calculation files, search for potential CO with subsequent identification (including, Cartographic) in the context of the results of the calculation. The procedure for preparing data is set out in the rules for assembling states that describe the basic technologies of the model used, with reference to information sources, in the rules for specifying dynamic relationships between neighboring states. The rules for assembling states are represented by a block of rules for transforming resources within territories, rules for transporting resources between them. The rules for specifying dynamic relationships between neighboring FEC states are represented by the characteristics of these states and the characteristics of 
the bonds themselves. The essence of the implementation of dynamic relationships is as follows:

1. Organization of separate modeling of static FEC states by reference years, separate modeling of dynamic relationships between formed static states.

2. The use of a unique unified encoding for modeling the static states of the fuel and energy complex, extended by additional identification of the temporal affiliation of states at the stage of calculation.

3. The use of a unique (different from the representation of the FEC states) a single encoding for modeling the dynamic relationships between states. Support for the typing of these links throughout the time interval, with reference to specific state technologies.

4. Support for the mechanism for defining dynamic relationships between neighboring time states in the form of "rules" describing the resources and technologies of the associated static states, resources and technologies of dynamic links of these states, including an auxiliary variable to reduce the coupling stiffness for debugging the model.

The research technology implemented in the module is represented by the following key stages:

1. The stage of the formation of initial data, including their automatic preparation on the basis of available sources (subject tables, subject databases), expert correction of the collected data, including a possible correction of the rules for specifying dynamic links.

2. The stage of preparation and execution of calculations, including the generation of autonomous states of the fuel and energy complex by reference years, the generation of communication equations between them, the formation of a single file in the solver format for subsequent calculations.

3. Representation and analysis of calculation results in tabular and cartographic form.

This technology completely reflects the iterative cycle of research, allows to obtain the existing solution taking into account the possible regulation of the rigidity of dynamic links.

\section{Experimental studies for estimation of the condition in critical infrastructures of energy in conditions of non-state situations}

With the use of developed models and software in the framework of research on the impact of energy security threats on reliable energy supply to consumers, a number of experimental calculations were carried out. The first cycle of calculations concerned the assessment of the state of the branch systems in the complex when the natural threat of "cooling" was realized in separate and in two neighboring regions. The next cycle of calculations was connected with the assessment of short supply of natural gas to regions from production centers in emergency situations complicated by distortions in the fuel and energy balance of European regions towards this resource.
The analysis of readiness to provide demand for boiler-furnace fuel (BFF), electric and thermal energy in the conditions of sharp cooling, was performed at the level of federal districts according to data on production and consumption for 2016 [13]. The calculations were carried out for the January days, corresponding to a $10 \%$ increase in the average daily heat and power demand in areas subject to peak temperatures. To such territories were assigned:

- alternately North-West, Ural, Siberian and FarEastern Federal Districts;

- the following combinations of federal districts: Northwest - Central, Northwest - Volga, Northwest Urals, Privolzhsky - Central, Volga - Urals, Privolzhsky - Southern, Ural - Siberian.

The characteristics of the obtained results are exemplified by the example of cooling in the Urals and Volga FD, Urals FD, presented at the level of relative daily deficits in BFF and heat (Fig. 4).

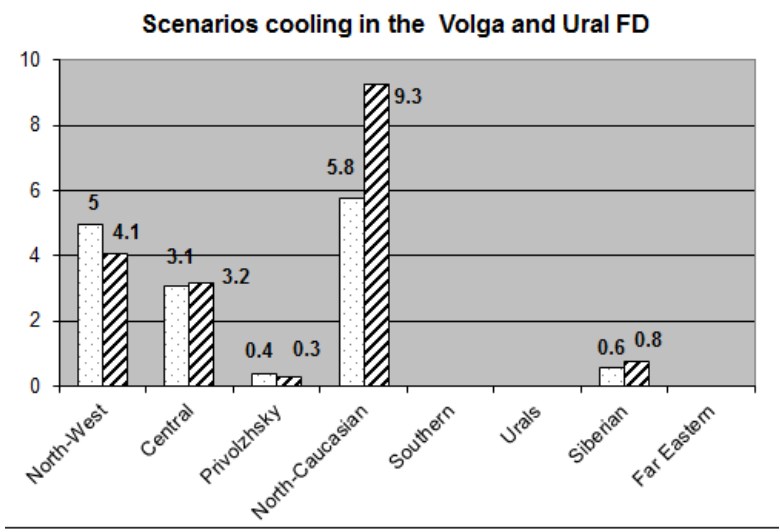

Scenarios cooling in the Ural FD

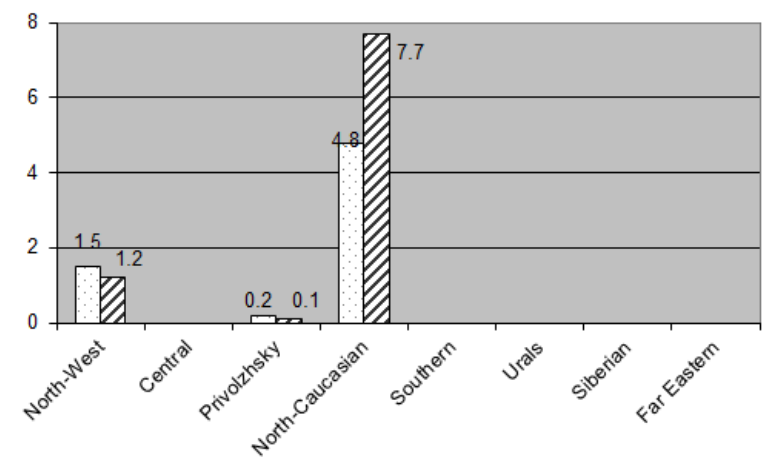

口Deficiency of BFF $\quad \square$ Deficiency of heat, $\%$

Fig. 4 Relative daily deficiency of BFF and heat in conditions of cold

The main regularity of these results is the emergence of a deficit among fuel consumers in the European regions of the country. And the main part is made up of natural gas, which is the main fuel in these regions. The increased demand for electricity, according to calculations, was repaid through diversification of electricity generation at various types of power plants and the use of reserves of generating capacity in the presence of fuel in thermal power plants. At the same time, the lack of gas at TPPs was compensated by the reserves of fuel oil. 
The second cycle of calculations was aimed at analyzing the consequences of accidents on non-trunk gas pipelines in the northern regions of the Urals Federal District, for which an average of more than six accidents per year is recorded. As calculations show, as a result of the accident in this region, characterized by a high density of gas transport flows, the potential shortage of gas to major consumers can be about $14 \%$ for the days of the accident. Most significantly, this shortfall can affect consumers in the North-West (short supply of gas - 37\%) and Central (short supply - 21\%) federal districts. The effect of the negative impact of an accident can be compensated by the interchangeability of fuels. The analysis of the results showed that, taking into account the possibilities of substituting gas with heating oil, taking into account the use of reserves and reserves in energy systems, the shortage of gas in the whole country in this situation will amount to $4.5 \%$ of the requirements of the period under review. The deficit of fuel oil in this case is $1.6 \%$. $\mathrm{n}$ general, this emergency situation can cause a deficit in consumers of fuel and energy resources at a rate of $2.8 \%$ of the total quarterly demand for them. Based on the calculations carried out, it can be argued that, given the existing share of gas in the European countries' fuel and energy unit, more than $70 \%$, negative consequences are possible due to the inability to compensate for missing gas volumes by other energy resources in a major accident on the main gas pipelines.

\section{Conclusion}

The model-tools presented in the article make it possible to carry out research to assess various contingencies in the fuel and energy complex and branch energy systems. The results obtained with their help confirm the working capacity of the created tools, the possibility of using them:

- to take into account inter-industry links in research on energy security;

- for the assessment of the state of energy and fuel and energy complex in emergency situations with different options for their development;

- to identify restrictions on energy facilities (transport, production, production, storage), which adversely affect the reliable fuel and energy supply to consumers.

The development of research involves the elaboration of a methodical tool for identifying potentially weak links in the fuel and energy complex that can significantly affect reliable energy supply to consumers and the behavior of computational experiments based on this apparatus.

\section{References}

1. Executive Order. 13010. Critical Infrastructure Protection. Federal Register. Vol. 61. №. 138. July 17, pp. 3747-3750 (1996)

2. S. Rinaldi, J. Peerenboom, and T. Kelly. IEEE Control Systems Magazine, IEEE, December, pp. 1125 (2001).

3. C. Keating, R. Rogers, D. Dryer, A. Sousa-Poza and other. Engineering Management Journal.Vol. 15, № 3 (2003).

4. Protect critical infrastructure. The concept of basic measures of protection https://www.google.ru/url? sa $=$ t\&rct=j\&q=\&esrc $=$ s\&so urce $=$ web\&cd $=1 \&$ ved $=0$ ahUKEwigkZ6K_PrSAhUCZ CwKHfWBAuIQFggcMAA\&url=https $\% 3 \mathrm{~A} \% 2 \mathrm{~F} \% 2 \mathrm{~F}$ www.bmi.bund.de $\% 2$ FSharedDocs $\% 2 F D o w n l o a d s \% 2$ FDE \%2FBroschueren\%2FSprachvarianten\%2FBasissc hutzkonzept_kritische_Infrastrukturen_russisch.pdf $\% 3$ $\mathrm{F}$ _blob\%3DpublicationFile\&usg=AFQjCNEjmCRfUt wKQGtk9uxHwqHBquPANA\&sig2=fS5phhQcKNaE4 1QBH_qSuQ\&cad=rjt

5. N.I. Pyatkova and others, Energy security of Russia: problems and solutions (SB RAS Publishing House, Novosibirsk, 2011)

6. V.I. Zorkaltsev, Methods for forecasting and analyzing the efficiency of the fuel supply system (Nauka, Moscow, 1988)

7. V.A.Sakovich, Optimal solutions to economic problems. (Vysh. School, Minsk, 1982).

8. M. Dunn, and I.Wigert. International CUP Handbook, An Inventory and Analysis of Protection Policies in Fourteen Countries. (Swiss Federal Institute of Technology, Zurich ,2004).

9. D. D. Dudenhoeffer, M. R. Permann, and M. Manic, Submitted to Proceedings of the 2006 Winter Simulation Conference, pp. 478-485 (2006)

10. N.I. Pyatkova, S.M. Senderov, E.V. Pyatkova, Izvestiya RAN. Power Engineering, 2, 7 (2014)

11. A.A. Makarov, L.A. Melentiev, Methods of research and optimization of the energy economy.(Nauka, Novosibirsk, 1973)

12. A.V. Edelev, S.M. Senderov, N.I. Pyatkova, Problems of management. 2, 7 (2015)

13. Ministry of Energy of the Russian Federatio, Statistics http://minenergo.gov.ru/activity/statistic. 